\title{
Exercise and postprandial lipemia: effects on vascular health in inactive adults
}

\author{
Robinson Ramírez-Vélez ${ }^{1 *}$ (D, María Correa-Rodríguez², Alejandra Tordecilla-Sanders', Viviana Aya-Aldana', \\ Mikel Izquierdo ${ }^{3}$, Jorge Enrique Correa-Bautista', Cristian Álvarez ${ }^{4,5}$ and Antonio Garcia-Hermoso ${ }^{6}$
}

\begin{abstract}
Background: There is evidence to suggest that postprandial lipemia are is linked to the impairment of endothelial function, which is characterized by an imbalance between the actions of vasodilators and vasoconstrictors. The aim of this study was to determine the effects of a 12-week high-intensity training (HIT) and moderate continuous training (MCT) protocol on postprandial lipemia, vascular function and arterial stiffness in inactive adults after high-fat meal (HFM) ingestion.
\end{abstract}

Methods: A randomized clinical trial was conducted in 20 healthy, inactive adults (31.6 \pm 7.1 years). Participants followed the two exercise protocols for 12 weeks. To induce a state of postprandial lipemia (PPL), all subjects received a HFM. Endothelial function was measured using flow-mediated vasodilation (FMD), normalized brachial artery FMD (nFMD), aortic pulse wave velocity (PW) and augmentation index (Alx). Plasma total cholesterol, high-density lipoprotein cholesterol (HDL-C), triglycerides and glucose were also measured.

Results: The effects of a HFM were evaluated in a fasted state and 60, 120, 180, and 240 min postprandially. A significant decrease in serum glucose between 0 min (fasted state) and 120 min postprandially was found in the HIT group $(P=0$. 035). Likewise, FMD (\%) was significantly different between the fasted state and 60 min after a HFM in the HIT group $(P=0.042)$. The total cholesterol response expressed as area under curve $(A \cup C)_{(0-240)}$ was lower following HIT than following $M C T$, but no significant differences were observed $(8 \%, P>0.05)$. Similarly, triglycerides $A \cup C_{(0-240)}$ was also lower after HIT compared with $M C T$, which trended towards significance $(24 \%, P=0.076)$. The $A \cup C_{(0-240)}$ for the glucose response was significantly lower following HIT than MCT $(10 \%, P=0.008)$. FMD and $\mathrm{nFMD} \mathrm{AUC}(0-240)$ were significantly higher following HIT than following MCT (46.9\%, $P=0.021$ and 67.3\%, $P=0.009$, respectively). PWV AUC (0-240) did not differ following between the two exercise groups $(2.3 \%, \mathrm{P}>0.05)$.

Conclusions: Supervised exercise training mitigates endothelial dysfunction and glucose response induced by PPL. Exercise intensity plays an important role in these protective effects, and medium-term HIT may be more effective than MCT in reducing postprandial glucose levels and attenuating vascular impairment.

Trial registration: ClinicalTrials.gov ID: NCT02738385 Date of registration: April 14, 2016.

Keywords: Postprandial lipemia, Endothelial function, Exercise intensity, High-intensity exercise, Moderate continuous training

\footnotetext{
* Correspondence: robin640@hotmail.com; robinson.ramirez@urosario.edu.co

${ }^{1}$ Centro de Estudios en Medición de la Actividad Física (CEMA), Escuela de

Medicina y Ciencias de la Salud, Universidad del Rosario, Bogotá, D.C,

Colombia

Full list of author information is available at the end of the article
} International License (http://creativecommons.org/licenses/by/4.0/), which permits unrestricted use, distribution, and reproduction in any medium, provided you give appropriate credit to the original author(s) and the source, provide a link to the Creative Commons license, and indicate if changes were made. The Creative Commons Public Domain Dedication waiver (http://creativecommons.org/publicdomain/zero/1.0/) applies to the data made available in this article, unless otherwise stated. 


\section{Background}

Postprandial lipemia (PPL) is defined as the elevation of circulating triglyceride-rich lipoproteins after high-fat meal (HFM) consumption. There is evidence to suggest that these exaggerated elevations in triglycerides are linked to impairment of endothelial function, characterized by an imbalance between the actions of vasodilators and vasoconstrictors [1]. Although the pathophysiology of endothelial dysfunction has not been fully clarified, reduced nitric oxide $(\mathrm{NO})$ and increased oxidative stress are important contributors to the reduction of the vasodilatory response [2].

Endothelial dysfunction induced by PPL is considered an early and reversible predictor of atherosclerotic disease and cardiac events [3, 4]. As humans spend a considerable part of the day in a postprandial state, interventions that can reduce the magnitude and duration of this metabolic state may be beneficial in the prevention of cardiovascular disease (CVD).

Exercise training prior to high-fat meal ingestion has been shown to have an attenuating effect on postprandial metabolism $[5,6]$. In the same line, studies have reported that energy expenditure through prior exercise is related to the magnitude of this effect $[7,8]$. Mestek et al. reported, however, that isocaloric sessions before a meal mitigate PPL independently of the intensity of the exercise session [9]. By contrast, other studies showed that the magnitude of PPL was influenced by prior exercise intensity $[5,10]$. Thus, the effects of the intensity of the exercise undertaken on postprandial response remain contentious.

With regard to postprandial endothelial function, evidence has shown that a single bout of exercise prior to HFM consumption improves fasting and postprandial endothelial function compared with a resting control condition [11-13]. Accordingly, it has been reported that acute moderate- and high-intensity exercise has transient benefits for macrovascular endothelial function in both fasting and postprandial states, and that these effects may be due to the improvement in antioxidant status $[14,15]$. Nevertheless, the limited prior studies carried out to investigate the effects of exercise intensity have produced inconsistent findings [15-17].

The aforementioned studies investigating the protective effects of exercise performed a few hours before consumption of an HFM on postprandial metabolism and endothelial function have focused on the acute effects of exercise. Thus, although a 12-week training program has been established as a protocol to assess the chronic effects of exercise [18], the potential impact on postprandial metabolism and vascular function after HFM have not been previously investigated. A recent narrative review summarized the current literature on the possible contributions of medium- to long-term physical training to the reduction of the postprandial response, concluding that the data are inconclusive [18]. Interestingly, a recent systematic review and meta-analysis on cardiometabolic health showed that performing even a short period ( 4 min) of high-intensity exercise has greater benefits than moderate-intensity exercise in terms of cardiometabolic risk factors [19].

Considering that most adults do not meet the public health recommendations of at least $150 \mathrm{~min}$ per week of moderate-intensity exercise and also that habitual physical activity declines during middle age [20], it is of special interest to identify how much high-intensity exercise is needed to optimize vascular function in adulthood.

Thus, we Given the above, we hypothesized that medium-term exercise could attenuate the postprandial decrement in metabolism and endothelial function and that this effect would differ according to exercise intensity. On this basis, we aimed to determine the effects of a 12-week high-intensity training (HIT) or a moderate continuous training (MCT) program on postprandial metabolism and vascular function and arterial stiffness after HFM ingestion in healthy, inactive Latin-American adults.

\section{Methods \\ Study design and setting}

Details of the study design and methods of the primary HIT-Heart Study trial have been described elsewhere (ClinicalTrials.gov ID: NCT02738385; April 14th, 2016) [21]. The study was performed in accordance with the Declaration of Helsinki (2000) and was approved by the local office for Medical Research Ethics Committee of The University of Santo Tomás, Colombia (ID 27-05002015). Postprandial biochemical and vascular function responses were assessed at baseline and over 12 weeks of training. We have previously provided an overview of the methods as per the Consolidated Standards of Reporting Trials (CONSORT) checklist [22].

\section{Participants}

Participants $(n=20)$ were recruited at the University of Rosario (Bogota, Colombia) from February 2015 to May 2016. Subjects were eligible to participate if they were located in the metropolitan region, with available time ( $1 \mathrm{~h}$ per day) to support the trial. Inclusion criteria were individuals aged 18-45 years who were inactive (< $150 \mathrm{~min} \cdot \mathrm{wk}^{-1}$ of moderate-intensity activity or $75 \mathrm{~min} \cdot \mathrm{wk}^{-1}{ }^{-1}$ of vigorous-intensity activity), had a body mass index (BMI) $\geq 18$ and $\leq 30 \mathrm{~kg} / \mathrm{m}^{2}$ and identified as being willing and having almost immediate availability. Individuals with a history of any medical condition identified by the American Heart Association as an absolute contraindication to exercise testing were excluded from the study [23]. Furthermore, individuals 
were also excluded if they presented any of the following: systemic infections, weight loss or gain of > $10 \%$ of body weight in the past 6 months for any reason, currently taking medication that suppresses or stimulates appetite, uncontrolled hypertension (systolic blood pressure $160 \mathrm{mmHg}$ or diastolic blood pressure $95 \mathrm{mmHg}$ ), gastrointestinal disease (including selfreported chronic hepatitis or cirrhosis, any episode of alcoholic hepatitis or alcoholic pancreatitis within the past year, inflammatory bowel disease requiring treatment in the past year, recent or significant abdominal surgery e. g., gastrectomy), asthma, diagnosed diabetes (type 1 or 2), fasting impaired glucose tolerance (blood glucose $\geq 118 \mathrm{mg} \cdot \mathrm{dl}^{-1}$ ), use of any prescribed drugs, any active use of illegal or illicit drugs, or inability to participate because of a physical impairment. In addition, two exercise physiologists tested whether subjects had alterations in ventricular function and/or cardiomyopathy, measured by standard 12-lead electrocardiography (ECG) at rest and every 3 min during a maximum treadmill exercise test. All subjects remained under usual medical care and clinical follow-up (i.e., regular appointments with a physician) throughout the protocol. All participants provided written informed consent before participating in the study.

\section{Blinding and randomization}

The coordinating Research Center for Physical Activity Measurement (CEMA) in Bogotá randomized the procedures with software using randomly permuted blocks. Group allocation was conducted via an online system in which the details of eligible participants were entered to obtain group assignments (i.e., 3:2 or 2:3). Assessors were blinded to study group assignments.

\section{Interventions}

After inclusion, patients performed a maximal cardiopulmonary exercise test on a maximum treadmill exercise test (Precor TRM 885, Precor Corp., Rome, Italy) following the modified Balke protocol [24]. Physiological parameters (maximal $\mathrm{O}_{2}$ consumption $\left[\mathrm{VO}_{2}\right]$, heart rate [HR] and Borg ratings) from the test were used to establish the exercise intensity. Based on averaged maximum $\mathrm{HR}(\mathrm{HRmax})$ and $\mathrm{VO}_{2}$ peak, the participants were classified according to normative values, referenced to age and sex. MCT and HIT interventions lasted 12 weeks, with 3 sessions per week consisting of fast walking or running on a treadmill with the deck inclined to reach the desired intensity. HR was recorded each session using an HR monitor (Polar Pacer, Polar Electro, Kempele, Finland). In addition, rating of perceived exertion (RPE) was also measured in each exercise session.

\section{Moderate continuous training (MCT) group}

Each preparatory period started with an exercise dose of $6 \mathrm{kcal} \cdot \mathrm{kg}^{-1} \cdot$ week $^{-1}$, which was increased progressively by $2 \mathrm{kcal} \cdot \mathrm{kg}^{-1} \cdot$ week $^{-1}$ until week 4 and was then maintained at $12 \mathrm{kcal} \cdot \mathrm{kg}^{-1} \cdot \mathrm{week}^{-1}$ for weeks 5 to 12 , which was equivalent to $300 \mathrm{kcal}$ of energy expended by the end of the training and cool-down $(3 \mathrm{~min})$ periods with total exercise time ranging from 45 to $55 \mathrm{~min}$. Exercise training sessions were designed to elicit a response in the acceptable moderate-to-vigorous range, that is, $60-75 \%$ of heart rate reserve (HRR), and were adjusted according to ratings on the Borg scale [25].. During the supervised intervention, $\mathrm{HR}$ was recorded using an $\mathrm{HR}$ monitor (Polar Pacer) to ensure compliance with the exercise stimulus at the predetermined target $\mathrm{HR}$ zone.

\section{High-intensity training (HIT) group}

We calculated training energy expenditures according to participants' age ranges and set the target energy expenditures to meet the consensus public health recommendations from the Cardiometabolic HIT-RT Study [25]. Each preparatory period started with an exercise dose of $6 \mathrm{kcal} \cdot \mathrm{kg}^{-1} \cdot \mathrm{week}^{-1}$, which was increased progressively by $2 \mathrm{kcal} \cdot \mathrm{kg}^{-1} \cdot$ week $^{-1}$ until week 4 and was then maintained at $12 \mathrm{kcal} \cdot \mathrm{kg}^{-1} \cdot$ week $^{-1}$ for weeks 5 to 12 . The overall goal for the HIT group was to perform exercise sessions in $4 \times 4$-min intervals at $85-95 \%$ of HRR (with the target zone maintained for at least $2 \mathrm{~min}$ ) , interspersed with a 4-min recovery period at $75-85 \%$ of HRR. During each exercise session, participants adhered to the $12 \mathrm{kcal} \cdot \mathrm{kg}^{-1} \cdot$ week $^{-1}$ energy expenditure format, which was equivalent to $300 \mathrm{kcal}$ of energy expended by the end of the training and cool-down (3 min) periods, with total exercise time ranging from 32 to $45 \mathrm{~min}$. During the supervised intervention, HR and Borg ratings were measured as described for the MCT group.

Both groups were instructed to refrain from exercise training and to avoid changing their physical activity levels outside the study. All participants reported adhering to these instructions. Although diet was not controlled, participants met with the study dietician for nutrition assessment and counseling at baseline, and an individualized iso-energetic nutrition intervention plan was developed from the baseline food intake assessment according to participant preferences. This plan was standardized at $1300-1500 \mathrm{kcal} \cdot \mathrm{day}^{-1}$ (50-55\% carbohydrates, $30-35 \%$ total fat, $<7 \%$ saturated fat and $15-22 \%$ protein), distributed across $3-4$ meals per day.

\section{Data collection and outcome measures Experimental procedure}

All measurements were performed at baseline and at the 12-week follow-up by personnel who were blinded to 
the treatment allocation. To control for confounding variables, we instructed the subjects to: i) fast for $10-$ $12 \mathrm{~h}$, ii) abstain from exercise for $24 \mathrm{~h}$, iii) abstain from caffeine, tobacco, and vitamin supplements for $12 \mathrm{~h}$, and iv) be awake between 0600 and $0700 \mathrm{~h}$, all prior to each testing session. The HFM, which has been previously reported [26], consisted of a breakfast containing $1049 \mathrm{cal}$ : $79 \mathrm{~g}$ of fat, $31 \mathrm{~g}$ of saturated fat, $4.5 \mathrm{~g}$ of trans fat, $666 \mathrm{mg}$ of cholesterol, $69 \mathrm{~g}$ of carbohydrates, $31 \mathrm{~g}$ of protein, and $2.22 \mathrm{mg}$ of sodium, adjusted by individual body weight. The effects of the HFM were measured in a fasted state and $60,120,180$, and 240 min postprandially. Figure 1 represents the schedule of experimental events for each subject.

\section{Biochemical parameters}

Blood was drawn from an antecubital vein. The biochemical profile included plasma total cholesterol, highdensity lipoprotein cholesterol (HDL-c), triglycerides and glucose (measured by enzymatic colorimetric methods). Inter-assay reproducibility (coefficients of variation) was determined via ten replicate analyses of five plasma pools over 15 days and was shown to be 2.0, 3.2, 2.6 and $1.5 \%$ for total cholesterol, HDL-c, triglycerides and serum glucose, respectively. All determinations were analyzed in serum using a Cardiocheck $^{\circ}$ and A1CNow $+{ }^{\circ}$ system.

\section{Vascular function and arterial stiffness measures}

All subjects were tested at the same time of day and after consumption of a low nitrate diet for $48 \mathrm{~h}$. Vascular function and arterial stiffness, as measured by flowmediated vasodilation (FMD), aortic pulse wave velocity (PWV) and the augmentation index (AIx) were measured. FMD was measured as described in previous studies from our group in the Colombian population [26] using the guidelines reported by Atkinson et al. [27]. The same operator performed all Doppler ultrasound (Mindray M-9 $9^{\circ}$ DS USA; Mahwah, NJ) examinations using a $7.5-\mathrm{MHz}$ linear array probe. Ultrasound imaging of the brachial artery was performed with the subjects in the supine position after $15 \mathrm{~min}$ of rest, with the arm abducted approximately $80^{\circ}$ from the body and the forearm supinated. The ultrasound probe was positioned with a $60^{\circ}$ insonation angle in a longitudinal plane at a site $1-3 \mathrm{~cm}$ proximal to the antecubital fossa to visualize the anterior and posterior lumen-intima interfaces, to measure diameter and central flow velocity (pulsed Doppler). After the baseline images were recorded, a blood pressure cuff, positioned on the arm, was inflated to $200 \mathrm{mmHg}$ for $5 \mathrm{~min}$; to assess FMD, images were acquired continuously for 3 min after cuff deflation, during the reactive hyperemia period. Brachial artery diameter recording was restarted at least $30 \mathrm{~s}$ before cuff deflation and continued for 3 min thereafter. The peak artery diameter and the time to reach this peak after cuff deflation were recorded. Images were recorded on a DVD for subsequent measurements by one observer blinded to the study design. FMD was calculated as the percent rise of peak diameter from the preceding baseline diameter and was measured every 1 min after deflation for $3 \mathrm{~min}$. Normalized brachial artery FMD (FMDn) was calculated according to the allometric relationship between the baseline artery diameter and the peak diameter [27]. The intra-session coefficient of variation was $\leq 1 \%$ for the baseline diameter. Reliability was estimated by intra-class correlation coefficients based on four baseline measurements ( $n=8$ subjects), yielding values of 0.91 for baseline diameter and 0.83 for FMD (our own data). The technical error of measurement was $1.23 \%$ for baseline diameter, $1.77 \%$ for maximum diameter and $20 \%$ for \%FMD.

The PWV was measured by analyzing the oscillometric pressure curves registered from the upper arm. Patient data and the measured distance between the jugulum and the symphysis were registered in an arteriographic computer program (Arteriograph Software v.1.9.9.2; TensioMed, Budapest, Hungary). A tape measure was used to measure the distance between the jugulum and the symphysis, the aortic distance. The cuff was placed on the patient's upper arm and connected to the device. The algorithm measuring blood pressure in the arteriography device has been previously validated [28]. PWV was calculated as the jugulum-to-symphysis distance (m) divided by one-half of the return time (return time/2) (s). For PWV measurements, the two recordings with

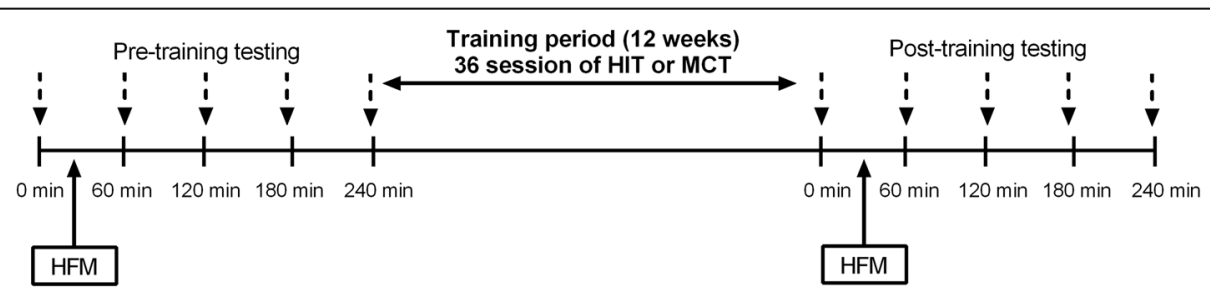

Fig. 1 Schedule of experimental events for each subject. HIT, high-intensity interval training; MCT, moderate-intensity continuous training; HFM, high-fat meal. Discontinuous arrows represent capillary blood samples and assessment of endothelial function 
the lowest standard deviations were chosen. The standard deviation was calculated on the basis of all heartbeats during a period of $8 \mathrm{~s}$.

The AIx was calculated as the ratio of the difference between the systolic peaks of the first pulse [1] and second pulse [2] relative to the central pulse pressure, expressed as a percentage [(pulse 2 - pulse 1/central pulse pressure $\times 100$ ]. Thus, it provides the brachial/ aortic AIx without applying a transfer function. The $\mathrm{R}$ value, used as an estimate of the measurement errors for the repeated measurements between two sessions, was low for the arteriograph $\left(1.18 \mathrm{~m} \cdot \mathrm{s}^{-1}\right)$.

\section{Statistical analysis}

To retain the data of all randomly allocated participants, we performed an intention-to-treat analysis (all randomly assigned patients). The Shapiro-Wilk test was used to verify data distribution normality. Once it was confirmed that the sample data satisfied the normality assumption, statistical analyses relevant to our main research interests were conducted. T-tests for continuous variables and chi-squared tests for categorical variables were used to investigate any possible differences in baseline characteristics between the two conditions (HIT and $\mathrm{MCT}$ ). We used a generalized linear model to analyze the influence of the different training protocols on biochemical and vascular function outcomes with repeated measures [2 (group) $\times 2$ (test time)]. The area under the curve (AUC), expressed in arbitrary units (au) via the trapezoidal method, was calculated and used to analyze the response to the training protocols. The effect of training on AUC measures was analyzed by two-way analysis of variance. Significant differences in AUC from 0 to 240 min after the HFM following 12 weeks of HIT or MCT were analyzed using two-way analysis of variance. A criterion alpha level of $P \leq 0.05$ was used to determine statistical significance. All data are reported as the mean \pm standard deviation. Statistical analyses were conducted using PASW Statistics 17 for Windows (SPSS, Inc., Chicago, IL).

\section{Results}

\section{Study participants}

Additional file 1: Figure S1 (Supplemental Digital Content) shows the flowchart of this randomized clinical trial. A total of 28 physically inactive subjects were assessed for eligibility, of which seven were excluded for not meeting the inclusion criteria. Of the 21 participants who started the study, 20 finished and one participant in the MCT group withdrew for reasons unrelated to the study (lack of time due to work schedule). Ten participants were randomly allocated to the MCT group, and 11 were randomly allocated to the HIT group.
The demographic features of the HIT and MCT groups, as well as their biochemical and endothelial function variables in the fasted state at baseline, are outlined in Table 1 . No statistically significant differences $(P>0.05)$ in baseline characteristics between the exercise training protocols were found (t-test), confirming that participants in both groups began the trial under similar conditions.

\section{Biochemistry and endothelial response}

Postprandial biochemical and endothelial function responses with summary measures of these responses after 12 weeks of HIT or MCT are shown in Table 2. A significant difference in glucose between 0 min (fasted state) and 120 min postprandially in the HIT group was found $(P=0.035)$. Likewise, \%FMD was significantly different between the fasted state and $60 \mathrm{~min}$ after HFM in the HIT group $(P=0.042)$.

Figure 2 shows the effects of HIT and MCT on total cholesterol, triglycerides and glucose postprandial responses, with summary measures of these responses. The total cholesterol response expressed as $\mathrm{AUC}_{(0-240)}$ was lower following HIT than following MCT, but no significant differences were observed $(8 \%, P>0.05)$. Similarly, triglycerides $\mathrm{AUC}_{(0-240)}$ was also lower following HIT than following MCT, with a trend toward significance $(24 \%, P=0.076)$. $\mathrm{AUC}_{(0-240)}$ for the glucose response was significantly lower following HIT than MCT $(10 \%, P=0.008)$.

Figure 3 shows the effects of HIT and MCT on FMD, nFMD and PWV postprandial responses, with summary measures of these responses. FMD and $\mathrm{nFMD} \mathrm{AUC}_{(0-}$ 240) were significantly higher following HIT than following MCT $(46.9 \%, P=0.021$ and $67.3 \%, P=0.009$, respectively). PWV AUC $(0-240)$ did not differ between HIT and MCT $(2.3 \%, \mathrm{P}>0.05)$.

No adverse events were reported during this study. As we have previously reported, the average exercisetraining days and total exercise time during the program were 35.5 days (SD 1.3) and $1100 \mathrm{~min}$ (SD 258) in the MCT group and 35.4 days (SD 0.9) and $1031 \mathrm{~min}$ (SD $147)$ in the HIT group $(P=0.043)$ [21].

\section{Discussion}

The aim of this study was to investigate the effects of chronic MCT and HIT on postprandial lipemia and vascular function and arterial stiffness after HFM consumption in inactive adults. The main finding of this study is that a 12-week regimen of HIT reduces glucose concentrations and exerts greater post-HFM endothelial function than MCT, supporting the idea that the effect of chronic exercise on postprandial response is dependent on exercise intensity [29]. 
Table 1 Demographic, biochemical and endothelial function variables in the fasted state across HIT and MCT groups at baseline

\begin{tabular}{|c|c|c|c|}
\hline Characteristics & $\mathrm{HIT}(n=11)$ & $\mathrm{MCT}(n=9)$ & $P$ value \\
\hline \multicolumn{4}{|l|}{ Sex, n (\%) } \\
\hline Male & $8(40.0)$ & $5(55.6)$ & 0.898 \\
\hline Female & $3(60.0)$ & $4(44.4)$ & 0.916 \\
\hline Age, mean (sd), y & $31.8(7.8)$ & $31.4(6.4)$ & 0.928 \\
\hline \multicolumn{4}{|l|}{ Biochemical parameters, mean (SD) } \\
\hline Total cholesterol (mg/dL) & $159.4(47.4)$ & $170.1(41.8)$ & 0.301 \\
\hline High-density lipoprotein (mg/dL) & $46.9(9.6)$ & $43.0(14.1)$ & 0.236 \\
\hline Triglycerides (mg/dL) & $100.4(36.8)$ & $134.1(82.2)$ & 0.118 \\
\hline Glucose (mg/dL) & $78.3(5.6)$ & $82.3(13.7)$ & 0.190 \\
\hline \multicolumn{4}{|l|}{ Vascular function parameters, mean (SD) } \\
\hline $\mathrm{D}_{\text {base, }} \mathrm{mm}$ & $3.0(0.6)$ & $2.7(0.4)$ & 0.157 \\
\hline FMD, \% & $7.2(3.3)$ & $7.3(5.6)$ & 0.487 \\
\hline$D_{\text {peak }} \mathrm{mm}$ & $3.2(0.5)$ & $3.0(0.5)$ & 0.140 \\
\hline$D_{\text {diff }}$ & $0.2(0.5)$ & $0.3(0.4)$ & 0.496 \\
\hline FMDn, \% & $6.5(2.9)$ & $7.4(5.7)$ & 0.433 \\
\hline $\mathrm{PW}, \mathrm{m} \cdot \mathrm{s}^{-1}$ & $6.7(0.8)$ & $7.1(1.2)$ & 0.204 \\
\hline Alx (aortic), \% & $41.7(10.4)$ & $24.5(32.7)$ & 0.148 \\
\hline Alx (brachial), \% & $16.5(5.2)$ & $25.1(16.5)$ & 0.152 \\
\hline Pulse Pressure $(\mathrm{mmHg})$ & $45.3(5.2)$ & $44.6(4.1)$ & 0.931 \\
\hline Central systolic blood pressure (mmHg) & $99.6(43.7)$ & $108.0(5.8)$ & 0.493 \\
\hline Pulmonary artery occlusion pressure (mmHg) & $40.6(6.8)$ & $35.6(3.9)$ & 0.087 \\
\hline Systolic blood pressure (mmHg) & $116.2(6.5)$ & $116.8(5.1)$ & 0.184 \\
\hline Diastolic blood pressure (mmHg) & $71.0(8.7)$ & $72.3(7.0)$ & 0.278 \\
\hline Mean blood pressure $(\mathrm{mmHg})$ & $86.0(7.6)$ & $87.3(6.0)$ & 0.482 \\
\hline
\end{tabular}

HIT $4 \times 4$-min high -intensity interval training, MCT moderate-intensity continuous training, $D$ diameter, FMD flow-mediated vasodilation, $n F M D$ normalized flowmediated vasodilation, PWV pulse wave velocity, Alx augmentation index

Recent evidence has shown that acute exercise increases FMD following HFM consumption [12, 30]. To the best of our knowledge, the present study is the first to demonstrate that medium-term exercise training prevents the decline in FMD induced by PPL, supporting the protective effect of regular exercise on vascular function. This is clinically relevant since endothelial function is an independent risk factor of CVD [3]. Interestingly, the higher AUC values of FMD in the HIT group after HFM $(P=0.009)$ indicates that this regimen may provide major vascular benefits in inactive adults.

In agreement with our results, previous studies focusing on the effect of acute exercise demonstrated that FMD remained greater after HFM consumption following a single bout of HIT as compared with MCT $[15,31]$. However, although it is of special interest to calculate incremental AUC values drawn from hourly measurements up to $4 \mathrm{~h}$ using the trapezoid rule [12, 32], most previous studies have not included these data. In contrast to our present findings, a recent study conducted in 11 physically active young men reported that FMD response did not differ between the two conditions [16]. The differences in training status between this study population (physically active) and our study cohort (inactive) might explain the inconsistent findings, since it has been shown that FMD responses after HFM consumption may differ between active and inactive subjects [33]. Thus, based on our results and previous research, it can be hypothesized that exercise attenuates the negative effects of HFM consumption on endothelial cell function in an inactive population. Further studies investigating the mechano-sensory mechanisms contributing to the effect of exercise on vascular function as well as possible interactions among molecular pathways are required [34].

The mechanism by which chronic exercise training can modulate postprandial endothelial function is unclear. Regular exercise has been proposed to decrease PPL and therefore reduce postprandial oxidative stress by maintaining low lipoprotein levels [35]. An alternative mechanistic explanation is that regular exercise might increase antioxidant capacity, leading to maintenance of endothelial function [15]. Indeed, a substantial increase 
Table 2 Intent-to-treat analysis of the effect of 12 weeks of HIT or MCT on postprandial lipemia biochemical and vascular function response after HFM ingestion

\begin{tabular}{|c|c|c|c|c|c|c|c|c|c|c|}
\hline & \multicolumn{5}{|l|}{ HIT } & \multicolumn{5}{|l|}{ MCT } \\
\hline & $0 \mathrm{~min}$ & $60 \mathrm{~min}$ & $120 \mathrm{~min}$ & $180 \mathrm{~min}$ & $240 \min$ & $0 \mathrm{~min}$ & $60 \mathrm{~min}$ & $120 \mathrm{~min}$ & $180 \mathrm{~min}$ & $240 \min$ \\
\hline \multicolumn{11}{|l|}{ Biochemical parameters } \\
\hline Total cholesterol (mg/dL) & $\begin{array}{l}151.3 \\
(21.0)\end{array}$ & $\begin{array}{l}159.0 \\
(28.1)\end{array}$ & $\begin{array}{l}159.0 \\
(30.2)\end{array}$ & $\begin{array}{l}163.2 \\
(30.0)\end{array}$ & $\begin{array}{l}164.8 \\
(20.2)\end{array}$ & $\begin{array}{l}153.1 \\
(29.09)\end{array}$ & $\begin{array}{l}158.6 \\
(25.1)\end{array}$ & $165.1(25.1)$ & $\begin{array}{l}166.8 \\
(25.0)\end{array}$ & $\begin{array}{l}167.1 \\
(29.4)\end{array}$ \\
\hline $\begin{array}{l}\text { High-density lipoprotein } \\
\text { (mg/dL) }\end{array}$ & $\begin{array}{l}46.0 \\
(14.1)\end{array}$ & $\begin{array}{l}47.3 \\
(14.6)\end{array}$ & $\begin{array}{l}46.1 \\
(12.7)\end{array}$ & $48.1(16.1)$ & $48.7(15.9)$ & $42.1(9.5)$ & $\begin{array}{l}44.2 \\
(11.6)\end{array}$ & $42.5(12.2)$ & $\begin{array}{l}41.6 \\
(12.6)\end{array}$ & $\begin{array}{l}40.5 \\
(10.9)\end{array}$ \\
\hline Triglycerides (mg/dL) & $\begin{array}{l}108.1 \\
(35.8)\end{array}$ & $\begin{array}{l}118.7 \\
(41.7)\end{array}$ & $\begin{array}{l}142.1 \\
(53.7)\end{array}$ & $\begin{array}{l}177.2 \\
(91.5)\end{array}$ & $\begin{array}{l}171.7 \\
(84.5)\end{array}$ & $\begin{array}{l}117.7 \\
(33.1)\end{array}$ & $\begin{array}{l}132.4 \\
(31.1)\end{array}$ & $\begin{array}{l}196.8 \\
(56.1)\end{array}$ & $\begin{array}{l}222.7 \\
(68.2)\end{array}$ & $\begin{array}{l}222.5 \\
(91.2)\end{array}$ \\
\hline Glucose (mg/dL) & $\begin{array}{l}76.4 \\
(11.0)\end{array}$ & $\begin{array}{l}78.8 \\
(12.9)\end{array}$ & $88.5(8.8)^{\mathrm{b}}$ & $84.3(7.8)$ & $86.3(5.0$ & $85.9(6.3)$ & $\begin{array}{l}93.6 \\
(12.4)\end{array}$ & $94.2(7.8)$ & $\begin{array}{l}93.3 \\
(10.3)\end{array}$ & $\begin{array}{l}89.5 \\
(10.7)\end{array}$ \\
\hline \multicolumn{11}{|l|}{ Vascular function parameters } \\
\hline$D_{\text {base, }}, \mathrm{mm}$ & $2.7(0.4)$ & $2.8(0.3)$ & $2.7(0.3)$ & $2.7(0.4)$ & $2.8(0.3)$ & $3.1(0.5)$ & $3.2(0.4)$ & $3.2(0.5)$ & $3.3(0.5)$ & $3.4(0.4)$ \\
\hline FMD, \% & $13.4(4.6)$ & $6.3(7.3)^{a}$ & $12.3(5.3)$ & $12.0(5.8)$ & $10.4(4.6)$ & $9.4(4.0)$ & $6.1(3.9)$ & $7.5(3.1)$ & $7.3(5.7)$ & $6.7(4.5)$ \\
\hline$D_{\text {peak }} \mathrm{mm}$ & $3.0(0.3)$ & $2.9(0.3)$ & $3.1(0.3)$ & $3.0(0.3)$ & $3.1(0.4)$ & $3.4(0.5)$ & $3.4(0.5)$ & $3.4(0.4)$ & $3.6(0.5)$ & $3.6(0.4)$ \\
\hline$D_{\text {diff }}$ & $0.3(0.2)$ & $0.1(0.1)$ & $0.4(0.3)$ & $0.3(0.2)$ & $0.3(0.2)$ & $0.3(0.2)$ & $0.2(0.1)$ & $0.2(0.1)$ & $0.3(0.2)$ & $0.2(0.1)$ \\
\hline nFMD, $\%$ & $13.5(6.3)$ & $13.4(4.6)$ & $11.7(6.1)$ & $11.8(7.3)$ & $10.1(5.1)$ & $8.1(4.1)$ & $9.4(4.0)$ & $6.5(3.2)$ & $6.3(5.2)$ & $5.5(4.2)$ \\
\hline PWV, $m \cdot s^{-1}$ & $6.6(1.5)$ & $7.0(1.6)$ & $6.6(2.4)$ & $6.7(1.2)$ & $6.8(1.0)$ & $6.7(0.9)$ & $6.5(1.0)$ & $6.7(1.0)$ & $6.5(1.0)$ & $6.7(1.0)$ \\
\hline Alx (aortic), \% & $\begin{array}{l}26.3 \\
(14.6)\end{array}$ & $14.7(9.4)$ & $\begin{array}{l}15.9 \\
(12.1)\end{array}$ & $\begin{array}{l}18.3 \\
(12.5)\end{array}$ & $19.1(9.2)$ & $38.7(69.0)$ & $7.6(4.2)$ & $3.6(16.0)$ & $9.5(4.1)$ & $11.2(7.0)$ \\
\hline Alx (brachial), \% & $\begin{array}{l}-22.3 \\
(28.9)\end{array}$ & $\begin{array}{l}-45.2 \\
(18.7)\end{array}$ & $\begin{array}{l}-42.7 \\
(24.0)\end{array}$ & $\begin{array}{l}-38.1 \\
(24.8)\end{array}$ & $\begin{array}{l}-36.5 \\
(18.2)\end{array}$ & $\begin{array}{l}-41.7 \\
(16.5)\end{array}$ & $\begin{array}{l}-59.3 \\
(8.5)\end{array}$ & $\begin{array}{l}-34.6 \\
(45.0)\end{array}$ & $\begin{array}{l}-55.5 \\
(8.2)\end{array}$ & $\begin{array}{l}-52.0 \\
(13.8)\end{array}$ \\
\hline $\mathrm{PP}(\mathrm{mmHg})$ & $45.5(7.7)$ & $49.8(7.3)$ & $45.9(8.5)$ & $\begin{array}{l}48.5 \\
(10.4)\end{array}$ & $47.4(7.4)$ & $45.1(7.6)$ & $46.7(6.4)$ & $51.0(8.4)$ & $46.0(6.6)$ & $48.8(7.2)$ \\
\hline SBPao $(\mathrm{mmHg})$ & $\begin{array}{l}107.6 \\
(14.2)\end{array}$ & $\begin{array}{l}102.4 \\
(7.7)\end{array}$ & $\begin{array}{l}102.6 \\
(12.9)\end{array}$ & $\begin{array}{l}105.8 \\
(10.2)\end{array}$ & $\begin{array}{l}106.3 \\
(9.6)\end{array}$ & $104.3(7.3)$ & $\begin{array}{l}103.6 \\
(8.4)\end{array}$ & $104.5(6.1)$ & $\begin{array}{l}105.0 \\
(8.4)\end{array}$ & $\begin{array}{l}109.3 \\
(9.6)\end{array}$ \\
\hline PPao $(\mathrm{mmHg})$ & $40.6(6.6)$ & $39.0(3.4)$ & $36.9(7.1)$ & $39.7(6.3)$ & $39.3(5.1)$ & 30.7 (12.9) & $33.8(5.3)$ & $38.0(6.9)$ & $35.0(6.2)$ & $36.8(6.1)$ \\
\hline $\begin{array}{l}\text { Systolic blood pressure } \\
(\mathrm{mmHg})\end{array}$ & $\begin{array}{l}112.5 \\
(9.1)\end{array}$ & $\begin{array}{l}113.2 \\
(6.4)\end{array}$ & $\begin{array}{l}111.5 \\
(8.4)\end{array}$ & $\begin{array}{l}114.6 \\
(7.2)\end{array}$ & $\begin{array}{l}114.3 \\
(6.6)\end{array}$ & $113.0(7.6)$ & $\begin{array}{l}116.4 \\
(9.1)\end{array}$ & $118.6(6.1)$ & $\begin{array}{l}117.0 \\
(8.1)\end{array}$ & $\begin{array}{l}121.2 \\
(10.8)\end{array}$ \\
\hline $\begin{array}{l}\text { Diastolic blood pressure } \\
(\mathrm{mmHg})\end{array}$ & $\begin{array}{l}67.0 \\
(10.3)\end{array}$ & $63.4(8.8)$ & $\begin{array}{l}65.6 \\
(11.4)\end{array}$ & $66.1(9.1)$ & $67.0(8.0)$ & $67.8(9.4)$ & $69.7(6.2)$ & $66.5(6.6)$ & $\begin{array}{l}71.0 \\
(11.7)\end{array}$ & $72.4(6.8)$ \\
\hline $\begin{array}{l}\text { Mean blood pressure } \\
(\mathrm{mmHg})\end{array}$ & $82.0(9.2)$ & $80.0(7.4)$ & $80.8(9.7)$ & $82.2(7.0)$ & $82.9(6.7)$ & $82.8(7.8)$ & $85.3(6.8)$ & $83.7(5.2)$ & $\begin{array}{l}86.2 \\
(10.2)\end{array}$ & $88.7(7.7)$ \\
\hline
\end{tabular}

Values are participant characteristics at baseline, mean (SD). HIT4 $\times 4$-min high-intensity interval training, MCT moderate-intensity continuous training, $D$ diameter, FMD flow-mediated vasodilation, FMDn, normalized flow-mediated vasodilation, $P W V$ pPulse wave velocity, Alx, augmentation index, $P P$ pulse pressure, SBPao central systolic blood pressure. PPao, pulmonary artery occlusion pressure. Whole group repeated measures ANOVA, $a=0$ min vs 60 min; $b=0$ min 120 min

in exercise intensity has been linked to greater protection of vascular function against oxidative stress, supporting the possibility that HIT might trigger larger vascular effects at the cellular and molecular levels [15]. Likewise, exercise might exert a positive effect on endothelial function by stimulating the production and bioavailability of $\mathrm{NO}$, as physical activity induces the activity of endothelial NO synthase (eNOS), increases the capacity of the cellular antioxidant system and diminishes the formation of reactive oxygen species (ROS) [36]. In addition, it has been demonstrated that a single session of exercise increased circulating and intramuscular free radical levels [37], which may lead to inactivation of $\mathrm{NO}$ with consequences for endothelium-mediated vasodilation [38]. It seems that acute exercise mediates the oxidant-antioxidant balance in favor of antioxidants, resulting in the maintenance of vascular function, and a similar effect is observed from the co-ingestion of antioxidants [39]. Thus, it is tempting to speculate that the effects of different intensities of exercise on postprandial FMD are related to changes in antioxidant status.

We also found that medium-term HIT decreased the glucose response over the postprandial observation period by $10 \%$ compared with MCT $(P=0.008)$, indicating that the 7 magnitude of postprandial glucose response was dependent on exercise intensity. This result contrasts with previous reports that failed to find differences 

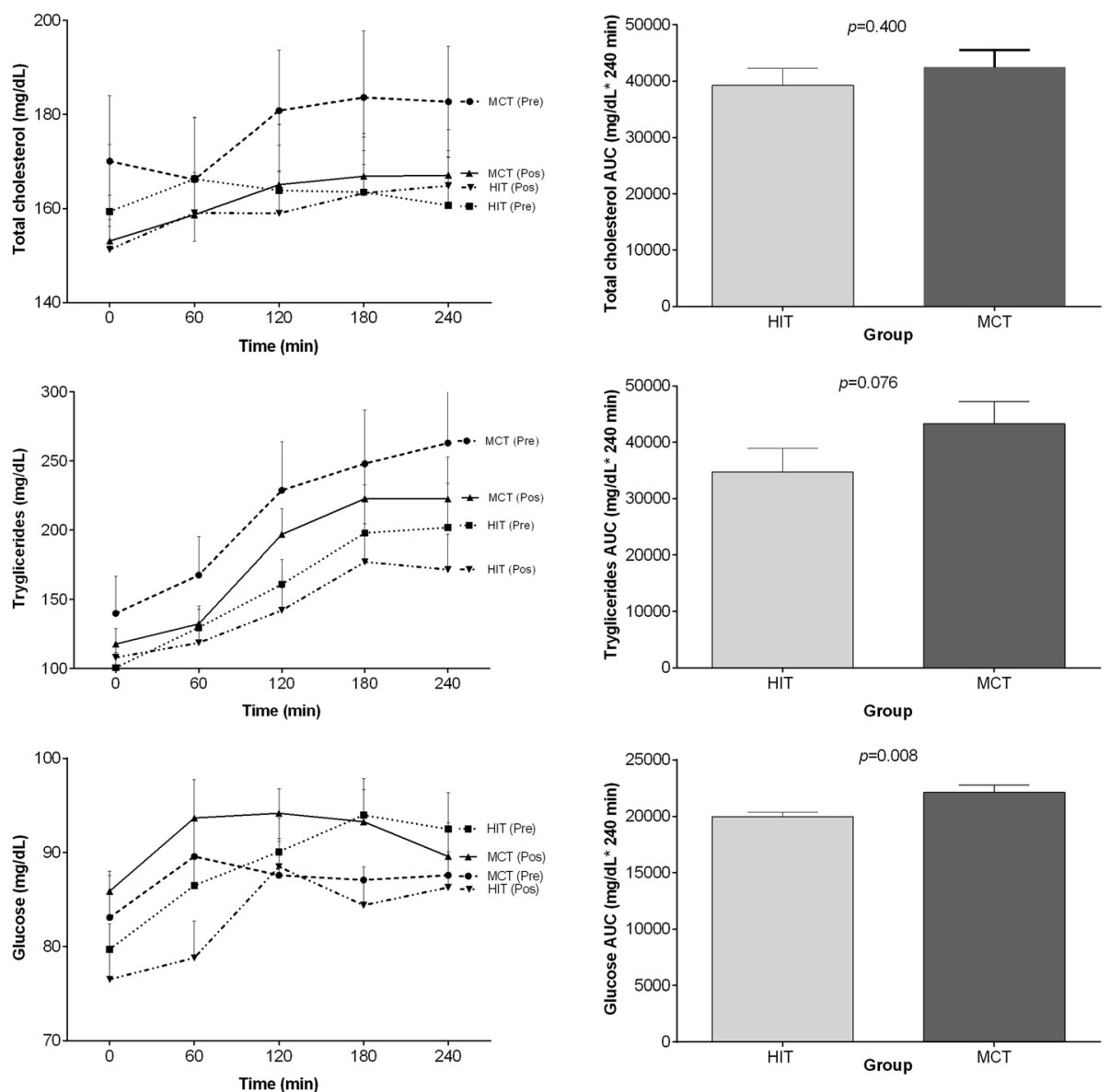

Fig. 2 Total cholesterol, triglycerides (TG) and glucose responses to PPL (left) and incremental AUC (right) after 12 weeks of HIT and MCT. Deviations from fasting were analyzed by repeated-measures ANOVA. Differences between total cholesterol, TG and glucose AUC $(0-240)$ after 12 weeks of HIT of MCT were analyzed by two -way analysis of variance

between the two training protocols regarding postprandial glucose levels $[10,15,16]$. However, it should be noted that these studies only examined the effect of postprandial glucose level after acute exercise. Thus, it is possible that only medium or long-term training has a significant effect on postprandial glucose response.

We found similar total cholesterol, HDL-c and triglyceride responses after HFM consumption in both training regimens, suggesting that medium-term exercise training might not play an important role in the postprandial decrement in lipid responses. In previous studies focusing on acute exercise, significant differences between HIT and MCT were found for triglycerides, but not for total cholesterol or HDL levels [10, 15, 16]. In this context, results from preliminary studies have suggested that the positive effect of exercise training on PPL might be short lived, demonstrating variations in the effect sizes for exercise training performed within $24 \mathrm{~h}$ prior to HFM ingestion and for exercise training performed more than $24 \mathrm{~h}$ pre-prandial $[8,40]$. Thus, we hypothesize that postprandial triglyceride response might be short lived, showing a relevant effect only after acute exercise.

\section{Study limitations}

This study has some limitations. Due to the high sensitivity of endothelium to nutritional changes, it would be ideal to administer isocaloric meals to participants at least three days before the measurement of endothelial function. In this study, although diet was not controlled, a dietician provided an individualized iso-energetic nutrition intervention plan. Second, since endothelial function is well known to be affected by age and training status and our study cohort comprised healthy, inactive mature adults, our findings may not be generalizable to other populations with different characteristics. A final possible limitation is that we did not examine other factors such as antioxidant status, NO, IL-6 and TNF- $\alpha$ levels that might ameliorate postprandial response, and this should be studied in future research. 

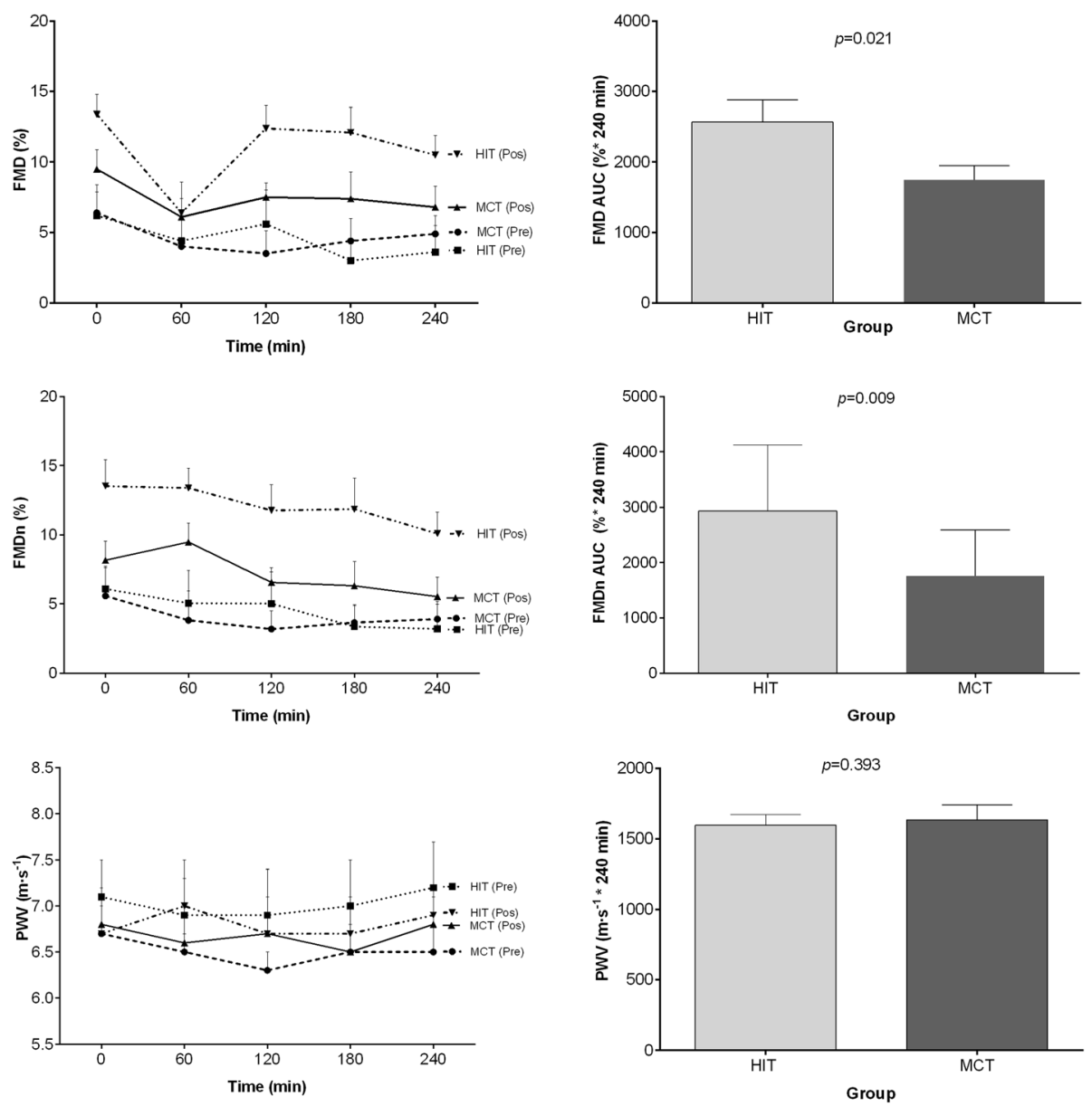

Fig. 3 FMD (\%), FMDn (\%) and PWV responses to PPL (left) and incremental AUC (right) after 12 weeks of HIT and MCT. Deviations from fasting were analyzed by repeated-measures ANOVA. Differences between FMD (\%), FMDn (\%) and PWV AUC(0-240) after 12 weeks of HIT of MCT were analyzed by two-way analysis of variance

The main strength of our study is that, to our knowledge, this is the first randomized clinical trial on the effect of exercise-training intensity on biochemical parameters and endothelial functional responses to HFM consumption in inactive adults from the Latin-American population. In addition, we provide measurements of these PPL responses at multiple time points to better describe their time course after chronic exercise.

\section{Conclusion}

In summary, the novel finding of this study was that medium-term supervised physical training may mitigate endothelial dysfunction and glucose response induced by PPL. Exercise intensity seems to play an important role in these protective effects, suggesting that HIT might be the more effective in reducing postprandial glucose levels and attenuating vascular impairments. Therefore, mediumterm HIT is an effective strategy to reduce CVD.

\section{Additional file}

Additional file 1: Figure S1. CONSORT guidelines flow diagram for enrolment and randomization. (TIFF $1515 \mathrm{~kb}$ )

\section{Acknowledgements}

We would like to thank and acknowledge the enthusiastic group of test participants who made this study possible.

\section{Funding}

This study as funded in part by the Center for Studies on Measurement of Physical Activity, School of Medicine and Health Sciences, Universidad del Rosario (Code No FIUR DN-BG001). We declare that the results of the study are presented clearly, honestly, and without fabrication, falsification, or appropriate data manipulation.

\section{Availability of data and materials}

The datasets used and/or analyzed during the present study are available from the corresponding author on reasonable request.

\section{Authors' contributions}

RR- $V$ conceived and designed the project. RR- $V$, and JEC-B, reviewed the literature studies and conducted data extraction. RR-V, JEC-B and VA-A 
conducted data analyses. RR-V, MC-R and MI were responsible for data interpretation. AT-S, MC-R and RR-V drafted the manuscript, and MI revised it critically for intellectual contributions. MI and RR-V coordinated the study development. All authors reviewed and edited the manuscript. All authors read and approved the final manuscript.

\section{Ethics approval and consent to participate}

Details of the study design and methods of the primary HIT-Heart Study tria have been described elsewhere (ClinicalTrials.gov ID: NCT02738385; April 14th, 2016). The study was performed in accordance with the Declaration of Helsinki (2000) and was approved by the local office for Medical Research Ethics Committee of The University of Santo Tomás, Colombia (ID 27-0500-2015). All participants provided written informed consent before participating in the study.

\section{Consent for publication}

Not applicable.

\section{Competing interests}

The authors declare that they have no competing interests.

\section{Publisher's Note}

Springer Nature remains neutral with regard to jurisdictional claims in published maps and institutional affiliations.

\section{Author details}

${ }^{1}$ Centro de Estudios en Medición de la Actividad Física (CEMA), Escuela de Medicina y Ciencias de la Salud, Universidad del Rosario, Bogotá, D.C, Colombia. ${ }^{2}$ Faculty of Health Sciences, University of Granada, Granada, Spain. ${ }^{3}$ Department of Health Sciences, Public University of Navarre, CIBER de Fragilidad y Envejecimiento Saludable (CB16/10/00315), Tudela, Navarre, Spain. ${ }^{4}$ Department of Physical Activity Sciences, Universidad de Los Lagos, Osorno, Chile. ${ }^{5}$ Research Nucleus in Health, Physical Activity and Sports, Universidad de Los Lagos, Osorno, Chile. '́ Laboratorio de Ciencias de la Actividad Física, el Deporte y la Salud, Facultad de Ciencias Médicas, Universidad de Santiago de Chile, USACH, Santiago, Chile.

\section{Received: 1 February 2018 Accepted: 25 March 2018} Published online: 03 April 2018

\section{References}

1. Endemann DH, Schiffrin EL. Endothelial dysfunction. J Am Soc Nephrol. 2004;15(8):1983-92.

2. Tousoulis D, Kampoli A-M, Tentolouris C, Papageorgiou N, Stefanadis C. The role of nitric oxide on endothelial function. Curr Vasc Pharmacol. 2012;10(1):4-18.

3. Mudau M, Genis A, Lochner A, Strijdom H. Endothelial dysfunction: the early predictor of atherosclerosis. Cardiovasc J Afr. 2012;23(4):222-31.

4. Borén J, Matikainen N, Adiels M, Taskinen MR. Postprandial hypertriglyceridemia as a coronary risk factor. Clin Chim Acta. 2014;431:131-42.

5. Freese EC, Gist NH, Cureton KJ. Effect of prior exercise on postprandial lipemia: an updated quantitative review. J Appl Physiol. 2014;116(1):67-75.

6. Zhang JQ, Thomas TR, Ball SD. Effect of exercise timing on postprandial lipemia and HDL cholesterol subfractions. J Appl Physiol. 1998;85(4):1516-22.

7. Gill JMR, Herd SL, Hardman AE. Moderate exercise and post-prandial metabolism: issues of dose-response. J Sports Sci. 2002;20(12):961-7.

8. Petitt DS, Cureton KJ. Effects of prior exercise on postprandial lipemia: A quantitative review. Metabolism. 2003;52(4):418-24.

9. Mestek ML, Plaisance EP, Ratcliff LA, Taylor JK, Wee S, Grandjean PW. Aerobic Exercise and Postprandial Lipemia in Men with the Metabolic Syndrome. Med Sci Sports Exerc. 2008;40(12):2105-11.

10. Littlefield LA, Papadakis Z, Rogers KM, Moncada-Jiménez J, Taylor JK Grandjean PW. The effect of exercise intensity and excess postexercise oxygen consumption on postprandial blood lipids in physically inactive men. Appl Physiol Nutr Metab. 2017;1-8.

11. Gill JMR, Al-Mamari A, Ferrell WR, Cleland SJ, Packard CJ, Sattar N, et al. Effects of prior moderate exercise on postprandial metabolism and vascular function in lean and centrally obese men. J Am Coll Cardiol. 2004;44(12): 2375-82.

12. Sedgwick MJ, Morris JG, Nevill ME, Barrett LA. Effect of repeated sprints on postprandial endothelial function and triacylglycerol concentrations in adolescent boys. J Sports Sci. 2015;33(8):806-16.
13. Chu A, Boutcher YN, Boutcher $\mathrm{SH}$. Effect of acute interval sprinting exercise on postprandial lipemia of sedentary young men. J Exerc Nutr Biochem. 2016;20(1):9-14

14. Harris RA, Padilla J, Hanlon KP, Rink LD, Wallace JP. The Flow-mediated Dilation Response to Acute Exercise in Overweight Active and Inactive Men. Obesity. 2008;16(3):578-84.

15. Tyldum GA, Schjerve IE, Tjønna AE, Kirkeby-Garstad I, Stølen TO, Richardson $\mathrm{RS}$, et al. Endothelial dysfunction induced by post-prandial lipemia: complete protection afforded by high-intensity aerobic interval exercise. J Am Coll Cardiol. 2009;53(2):200-6.

16. Lopes Krüger R, Costa Teixeira B, Boufleur Farinha J, Cauduro Oliveira Macedo R, Pinto Boeno F, Rech A, et al. Effect of exercise intensity on postprandial lipemia, markers of oxidative stress, and endothelial function after a high-fat meal. Appl Physiol Nutr Metab. 2016;41(12):1278-84.

17. Teeman CS, Kurti SP, Cull BJ, Emerson SR, Haub MD, Rosenkranz SK. The effect of moderate intensity exercise in the postprandial period on the inflammatory response to a high-fat meal: an experimental study. Nutr J. 2016;15(1):1-13.

18. Teeman CS, Kurti SP, Cull BJ, Emerson SR, Haub MD, Rosenkranz SK. Postprandial lipemic and inflammatory responses to high-fat meals: a review of the roles of acute and chronic exercise. Nutr Metab (Lond). 2016;13(1):80.

19. Batacan RB, Duncan MJ, Dalbo VJ, Tucker PS, Fenning AS. Effects of highintensity interval training on cardiometabolic health: a systematic review and meta-analysis of intervention studies. Br J Sports Med. 2017;51(6):494-503.

20. Kalman M, Inchley J, Sigmundova D, lannotti RJ, Tynjala JA, Hamrik Z, et al. Secular trends in moderate-to-vigorous physical activity in 32 countries from 2002 to 2010: a cross-national perspective. Eur J Public Health. 2015; 25(suppl 2):37-40.

21. Ramírez-Vélez R, Tordecilla-Sanders A, Téllez-T LA, Camelo-Prieto D, Hernández-Quiñonez PA, Correa-Bautista JE, et al. Effect of Moderate Versus High-Intensity Interval Exercise Training on Heart Rate Variability Parameters in Inactive Latin-American Adults. J Strength Cond Res [Internet]. 2017 Feb 1 [cited 2017 Jul 30];1. Available from: http://www.ncbi.nlm.nih.gov/ pubmed/28198783.

22. Campbell MK, Piaggio G, Elbourne DR, Altman DG, CONSORT Group. Consort 2010 statement: extension to cluster randomised trials. BMJ. 2012; 345:e5661.

23. Lauer M, Froelicher ES, Williams M, Kligfield P, American Heart Association Council on Clinical Cardiology, Subcommittee on Exercise, Cardiac Rehabilitation, and Prevention. Exercise Testing in Asymptomatic Adults: A Statement for Professionals From the American Heart Association Council on Clinical Cardiology, Subcommittee on Exercise, Cardiac Rehabilitation, and Prevention. Circulation. 2005;112(5):771-6.

24. Lloyd-Jones DM, Hong Y, Labarthe D, Mozaffarian D, Appel L, Van Horn L, et al. Defining and Setting National Goals for Cardiovascular Health Promotion and Disease Reduction: The American Heart Association's Strategic Impact Goal Through 2020 and Beyond. Circulation. 2010;121(4): 586-613.

25. Ramírez-Vélez R, Tordecilla-Sanders A, Téllez-T LA, Camelo-Prieto D, Hernández-Quiñonez PA, Correa-Bautista JE, et al. Similar cardiometabolic effects of high- and moderate-intensity training among apparently healthy inactive adults: a randomized clinical trial. J Transl Med. 2017;15(1):118.

26. Ramírez-Vélez R. Postprandial lipemia induces endothelial dysfunction and higher insulin resistance in healthy subjects. Endocrinol Nutr. 2011;58(10):529-35.

27. Corretti MC, Anderson TJ, Benjamin EJ, Celermajer D, Charbonneau F, Creager MA, et al. Guidelines for the ultrasound assessment of endothelialdependent flow-mediated vasodilation of the brachial artery: a report of the International Brachial Artery Reactivity Task Force. J Am Coll Cardiol. 2002; 39(2):257-65.

28. Ring M, Eriksson MJ, Zierath JR, Caidahl K. Arterial stiffness estimation in healthy subjects: a validation of oscillometric (Arteriograph) and tonometric (SphygmoCor) techniques. Hypertens Res. 2014;37(11):999-1007.

29. Early KS, Stewart A, Johannsen N, Lavie CJ, Thomas JR, Welsch M. The Effects of exercise training on brachial artery flow-mediated dilation. J Cardiopulm Rehabil Prev. 2017;37(2):77-89.

30. Sedgwick MJ, Morris JG, Nevill ME, Barrett LA. The accumulation of exercise and postprandial endothelial function in boys. Scand J Med Sci Sport. 2014; 24(1):301-9.

31. Bond B, Gates PE, Jackman SR, Corless LM, Williams CA, Barker AR. Exercise intensity and the protection from postprandial vascular dysfunction in adolescents. Am J Physiol Heart Circ Physiol. 2015;308(11):H1443-50. 
32. Weiss EP, Fields DA, Mittendorfer B, Haverkort MAD, Klein S. Reproducibility of postprandial lipemia tests and validity of an abbreviated 4-hour test. Metabolism. 2008:57(10):1479-85.

33. Johnson BD, Padilla J, Harris RA, Wallace JP. Vascular consequences of a high-fat meal in physically active and inactive adults. Appl Physiol Nutr Metab. 2011;36(3):368-75.

34. Whyte JJ, Laughlin MH. The effects of acute and chronic exercise on the vasculature. Acta Physiol (Oxf). 2010;199(4):441-50.

35. Westphal S, Taneva E, Kästner S, Martens-Lobenhoffer J, Bode-Böger S, Kropf $S$, et al. Endothelial dysfunction induced by postprandial lipemia is neutralized by addition of proteins to the fatty meal. Atherosclerosis. 2006; 185(2):313-9.

36. Maeda S, Miyauchi T, Kakiyama T, Sugawara J, lemitsu M, IrukayamaTomobe $Y$, et al. Effects of exercise training of 8 weeks and detraining on plasma levels of endothelium-derived factors, endothelin-1 and nitric oxide, in healthy young humans. Life Sci. 2001;69(9):1005-16.

37. Bailey DM, Lawrenson L, Mceneny J, Young IS, James PE, Jackson SK, et al. Electron paramagnetic spectroscopic evidence of exercise-induced free radical accumulation in human skeletal muscle. Free Radic Res. 2007;41 (2):182-90.

38. Ji LL. Exercise-induced modulation of antioxidant defense. Ann N Y Acad Sci. 2002;959:82-92.

39. Plotnick GD, Corretti MC, Vogel RA. Effect of antioxidant vitamins on the transient impairment of endothelium — dependent brachial artery vasoactivity following a single high-fat meal. JAMA. 1997;278(20):1682.

40. Zhang JQ, Ji LL, Nunez G, Feathers S, Hart CL, Yao WX. Effect of exercise timing on postprandial lipemia in hypertriglyceridemic men. Can J Appl Physiol Can J Appl Physiol. 2004;29(5):590-603.

\section{Submit your next manuscript to BioMed Central and we will help you at every step:}

- We accept pre-submission inquiries

- Our selector tool helps you to find the most relevant journal

- We provide round the clock customer support

- Convenient online submission

- Thorough peer review

- Inclusion in PubMed and all major indexing services

- Maximum visibility for your research

Submit your manuscript at www.biomedcentral.com/submit 